\title{
EFFECTIVITY OF INJECTION SCLEROTHERAPY ON EARLY HAEMORRHOIDS REPORTED TO SURGICAL OUTPATIENT DEPARTMENT
}

\author{
Bhuiya $\mathrm{MFA}^{1}$, Rahman $\mathrm{S}^{2}$, Ali A ${ }^{3}$
}

\begin{abstract}
This prospective study was carried out at a Military Hospital over a period of 10 months. Total 96 cases of first degree and early second degree haemorrhoid cases treated by injection sclerotherapy were included in this study. Among them, first degree haemorrhoids were $60 \%$ cases and early second degree haemorrhoids were $40 \%$ cases. The highest number of patients was in 3rd and 4th decade (81\%). After adequate bowel preparation, under proctoscopy three positions of haemorrhoids were identified. By a Gabrial syringe 5\% phenol in olive oil (3-5 ml) was injected in the submucosa of the pedicle of each haemorrhoid. The patients were followed up monthly for six months. All the patients were presented with painless per rectal bleeding. Constipation was present in $89 \%$ cases. Satisfactory result was observed in $60 \%$ cases and out of them 40 cases were having first degree haemorrhoids and rest of the cases were having early second degree haemorrhoids. Second dose of injection was required in 38 cases and third dose of injection was required in 32 cases. Out of 38 patients who received second dose of injection, only 6 patients had satisfactory outcome and almost all but one patient who received third dose of injection showed unsatisfactory result. Reported method is easy, convenient, cheap and effectively practicable at outdoor level.
\end{abstract}

Key words : Haemorrhoid, sclerotherapy, satisfactory outcome

\section{Introduction}

Haemorrhoid is the most frequent problem in clinical practice of general surgery. Patients do not always need treatment if the symptoms are minimal ${ }^{1,2}$. Treatment modalities of haemorrhoid are nonoperative and operative treatment. In nonoperative treatment, bowel movement is regulated by hydrophilic colloids (isogel etc) and various proprietary creams can be inserted into the rectum from a collapsible tube fitted with a nozzle with hip bath. Active treatment of haemorrhoids consists of injection sclerotherapy, elastic band application to the base of each haemorrhoid, cryosurgery, laser therapy, photocoagulation (infrared coagulation) and formal operation $^{2}$. Injection treatment is ideal for first degree internal bleeding haemorrhoids. Early second degree haemorrhoids are often cured by this method, but may relapse. The clear advantages of the modern methods for outpatient treatment of internal haemorrhoids are that they are less time consuming and procedures are relatively painless. Patients soon return to work, the complications are minor and the cure rate is $\operatorname{high}^{3,4}$. The aim and objective of this study was to evaluate the outcome of injection sclerotherapy in first degree and early second degree haemorrhoids.

\section{Materials and Methods}

This prospective study was carried out at Combined Military Hospital (CMH) of Comilla Cantonment during the period of November 2009 to August 2010. All the adult patients reported to the surgical outpatient department (SOPD) with first degree and early second degree haemorrhoids were included in this study. Patients with known cardiac, liver and renal diseases and with psychiatric problem and hypersensitive to phenol were excluded from the study. Informed written consent was taken from each patient. Adequate bowel preparation was ensured by syrup lactolose 2 tea-spoonfull (tsf) 8 hourly for two days. Proctoscopy was done in left lateral position. Positions of the right anterior, right posterior and left lateral haemorrhoids were identified. By a Gabrial syringe 3-5 $\mathrm{ml}$ of 5\% phenol in olive oil was injected in the submucosa of the pedicle of each haemorrhoid to produce a swelling with a pearly appearance of the mucosa. Injection sites were pressed with cotton wool to minimize leakage. All the patients were advised to have tablet ciprofloxacin $500 \mathrm{mg} 12$ hourly and tablet paracetamol if indicated and syrup lactolose 2 tsf 8 hourly orally for next 7 days. Patients were reexamined after 7 days of injection. Subsequently followed up every 15 days for two months and then monthly for next six months. Second and third dose of injection were administrated after six weeks and twelve weeks respectively in some cases. All the data were collected in a preformed data sheet and analyzed by statistical package of social science (SPSS). 


\section{Results}

Age distribution of the patients showed that highest number of the patients $46(47.92 \%)$ were in the age group of 21-30 years (Table-I).

Table-I: Distribution of patients according to age group $(\mathrm{n}=96)$.

\begin{tabular}{|l|c|c|}
\hline $\begin{array}{l}\text { Age group } \\
\text { (in years) }\end{array}$ & $\begin{array}{c}\text { Number of } \\
\text { patients }\end{array}$ & Percentage \\
\hline $21-30$ & 46 & 47.92 \\
\hline $31-40$ & 32 & 33.33 \\
\hline $41-50$ & 14 & 14.58 \\
\hline$>50$ & 04 & 04.17 \\
\hline
\end{tabular}

Out of 96 patients $72(75 \%)$ were male and 24 (25\%) were female. Male female ratio was 3: 1 . All the patients presented with painless per-rectal bleeding. Constipation was present in $85(88.54 \%$ ) cases (Table-II).

Table- II : Clinical presentation of the patients $(\mathrm{n}=96)$

\begin{tabular}{|l|c|c|}
\hline Clinical presentation & $\begin{array}{c}\text { Number of } \\
\text { patients }\end{array}$ & Percentage \\
\hline Per rectal bleeding & 96 & 100.00 \\
\hline Constipation & 85 & 88.54 \\
\hline Discomfort & 11 & 11.46 \\
\hline pain & 08 & 08.33 \\
\hline
\end{tabular}

Table -III : Distribution of patients according to the nature of job $(n=96)$.

\begin{tabular}{|l|c|c|}
\hline Nature of job & No of patients & Percentage \\
\hline Sedentary job & 52 & 54.17 \\
\hline $\begin{array}{l}\text { Job of prolonged } \\
\text { standing, heavy work, } \\
\text { weight lifting etc. }\end{array}$ & 44 & 45.83 \\
\hline
\end{tabular}

Majority of the patients $(54.17 \%)$ were doing sedentary job, rest $(45.83 \%)$ were engaged in heavy work or strenuous job. Out of 96 patients 57 (59.37\%) were having $1^{0}$ haemorrhoids and $39(40.63 \%)$ patients were having early $2^{0}$ haemorrhoids (Table-IV).

Table-IV : Distribution of patients according to the type of haemorrhoids $(n=96)$.

\begin{tabular}{|l|c|c|}
\hline Type of haemorrhoids & $\begin{array}{c}\text { No of } \\
\text { patients }\end{array}$ & Percentage \\
\hline $1^{0}$ haemorrhoids & 57 & 59.37 \\
\hline Early $2^{0}$ haemorrhoids & 39 & 40.63 \\
\hline
\end{tabular}

During the procedure only $2(2.08 \%)$ patients had history of bleeding which was stopped by anal pack. Complications like prostatitis, infection or ulceration were not observed in any case.
Table -V: Number of injections required for satisfactory result.

\begin{tabular}{|c|c|c|c|c|}
\hline $\begin{array}{c}\text { No of } \\
\text { injection }\end{array}$ & $\begin{array}{c}\mathbf{1}^{\mathbf{0}} \\
(\mathbf{n}=\mathbf{5 7})\end{array}$ & $\begin{array}{c}\text { Early 2 } \\
(\mathbf{n}=\mathbf{3 9})\end{array}$ & $\begin{array}{c}\text { Total } \\
(\mathbf{n = 9 6 )}\end{array}$ & $\begin{array}{c}\text { \% of } \\
\text { satisfactory } \\
\text { result }\end{array}$ \\
\hline 1st & $57(40)$ & $39(18)$ & $96(58)$ & 60.41 \\
\hline 2nd & $17(05)$ & $21(01)$ & $38(06)$ & 15.78 \\
\hline 3rd & $12(01)$ & $20(00)$ & $32(01)$ & 03.12 \\
\hline
\end{tabular}

* Numbers in parenthesis yield satisfactory result.

After first dose of injection $60.41 \%$ (58 patients) had satisfactory result. Rest 38 patients were given second dose of injection, of which only 6 patients $(15.78 \%)$ showed satisfactory result. Third dose of injection provided satisfactory result only in one patient $(3.12 \%)$ out of 32 cases.

\section{Discussion}

Dilatation of the internal venous plexus within an enlarged displaced anal cushion is called haemorrhoids ${ }^{5}$. Causes of haemorrhoids are hereditary or congenital weakness of the vein wall and absence of valves in the rectal veins. Higher anal pressures are also an aetiologic component in the formation of haemorrhoids ${ }^{6}$. Straining at constipation is responsible for increased anal pressure. Persistence of the anorectal band, a remnant of embryological anorectal sinus and failure of rectal neck remodeling are considered responsible for the initiation of the haemorrhoidal disease ${ }^{7}$. Johanson JF and Sonnenberg A studied 168 patients of haemorrhoids and no significant association was observed between constipation and haemorrhoids ${ }^{8}$. In this study constipation was observed in most of the cases (88.54\%) probably because of food habit of the patients (less intake of fibre containing diets). Constipation causes high internal anal pressure. So constipation is definitely related to the aetiology of haemorrhoids ${ }^{5}$.

Haemorrhoids are frequently arranged in three groups at 3, 7, and 11 o'clock positions with the patient in lithotomic position. Haemorrhoids that bleed but do not prolapse outside the anal canal is called the first degree haemorrhoids. Haemorrhoids that prolapse on defaecation which is reduced automatically or need to be reduced manually and then stay reduced is called second degree haemorrhoids. Third degree haemorrhoids remain permanently prolapsed ${ }^{2}$. In this study the age incidence of haemorrhoids was more in third and fourth decade with male predominance (male:female $=3: 1$ ). Rhee JC studied 970 cases of haemorrhoids and anal fissure, where author observed that the patients were mostly in and around 30 years of age which is comparable with this study ${ }^{9}$. There was no sex predominance in Rhee JC's study.

Bleeding is the principal and earliest symptom of 
haemorrhoids3. Other symptoms are prolapse, discharge of mucous, pruritus ani, local pain and very rarely anaemia. Prolapse is a much delayed symptom. Local pain is absent unless there is complication like strangulation and thrombosis. In this study bleeding was observed in all the patients $(100 \%)$. Mild pain was in 8 $(8.33 \%)$ patients and anal discomfort was in $11(11.46 \%)$ patients.

Proctoscope is the main instrument by which diagnosis is made. Active treatments of haemorrhoids are injection sclerotherapy, elastic band application (Barron), cryosurgery, photocoagulation and operative treatment ${ }^{2,3}$. Operative treatment is indicated in the case of third degree haemorrhoids or in case of failure of non operative treatment of second degree haemorrhoids. Injection sclerotherapy is indicated in first degree haemorrhoids, which bleed and in early second degree haemorrhoids ${ }^{2,5}$. If there is only one haemorrhoids present, it may be cured by one injection. If all three sites of haemorrhoids are equally enlarged, each shall be injected at one session. Often three sessions at six weekly intervals are required5. This study also revealed that out of 96 patients, $52(54.17 \%)$ patients were engaged in sedentary job, 44(45.83\%) patients were engaged in strenuous job. It suggests the military nature of job and food habit which demands strenuous physical activity in extremes of weather with less fluid and fibre rich food intake make the troops more vulnerable to this disease condition. The conditions mentioned above cause increased anal canal resting pressure as well as raised intra abdominal pressure. According to Williams and Bulstrode, there is definite association between raised anal canal resting pressure and haemorrhoids ${ }^{5}$.

Injection of 5\% phenol in almond oil as the sclerosing agent is the standard one but due to nonavailability of almond oil, olive oil was used in this study ${ }^{3}$. The commonly used sclerosants are not available or very expensive in Nigeria. So Alatise OI and team in a prospective study evaluated use of $50 \%$ dextrose water, as a non-allergenic sclerosant, in the treatment of bleeding internal hemorrhoids ${ }^{10}$. They observed very good result.

Immediate complications of injection sclerotherapy are bleeding, local pain, ulceration and prostatitis in case of male if injection is too deep and anterior. Prostatitis should be treated immediately with antibiotics. There may be late complication like fibrosis with anal canal stenosis. In this study immediate complication in the form of bleeding was observed in only $2(2.08 \%)$ cases. In this series not a single patient was observed to be anaemic due to haemorrhoidal bleeding. In Kluiber RM series incidence of haemorrhoidal bleeding that caused anaemia was found to be in 5 patients per 100,000 populations per year ${ }^{11}$. In this study satisfactory results were observed in 40 cases of first degree haemorrhoids and in 18 cases of early second degree haemorrhoids (total 60.41\%). Johanson JF and Rimm A treated 863 patients with injection sclerotherapy, rubber band legation, infrared coagulation and results demonstrated that similar number of patients were asymptomatic 12 months after treatment ${ }^{12}$.

\section{Conclusion}

Prevention is the best treatment of haemorrhoids. Diets high in fibre and bulk can prevent constipation. If the diet can not be modified in this way, adding bulk laxatives may be necessary, they can prevent worsening of the condition. There are numerous creams and suppositories that can relieve anal irritations and pain but they rarely provide long term benefit. Injection sclerotherapy is an effective method of treatment of first degree and early second degree haemorrhoids. This method is easy, convenient and cheap. It can be done at outpatient department. This method is well accepted and comfortable for the patient. Virtually there is no complication, no loss of work and the result is also satisfactory.

\section{References}

1. RM Kirk. General surgical operations. 4th ed. London: Churchill Livingstone; 2000. p.353-358.

2. Acheson AG, Scholefield JH. Management of haemorrhoids. BMJ 2008 Feb 16; 336(7640): 380-3.

3. Zinberg SS, Stern DH, Furman DS, Wittles JM. A personal experience in comparing three nonoperative techniques for treating internal haemorrhoids. Am J Gastroenterol 1989, 84: 488-92.

4. Ohning GV, Machicado GA, Jensen DM. Definitive therapy for internal hemorrhoids--new opportunities and options. Rev Gastroenterol Disord 2009 Winter; 9(1):16-26.

5. Mann CV, Russel RCG, Williams NS. Bailey and Love's Short Practice of Surgery. 22nd ed . London : ELBS ( Chapman and Hall ); 1995. p.471-477.

6. Deutsch AA, Moshkovitz M, Nudelman I, Dinari G, Reiss R . Anal pressure measurements in the study of haemorrhoid aetiology and their relation to treatment. Dis Colon Rectum. 1987 Nov, 30 ( 11 ) : 855 -7 .

7. Shafik A. A new concept of the anatomy of the anal sphincter mechanism and the physiology of defaecation. Treatment of haemorrhoids : report of a technique . Am J Surg 1984 Sep; 148(3): 393-8.

8. Johanson JF , Sonnenberg A . Constipation is not a risk factor for haemorrhoid : a case control study of potential aetiological agents . Am J Gastroenterol 1994 Nov; 87(11): 1981-6 .

9. Rhee JC, Lee KT .The causes and management of lower GI bleeding : a study based on clinical observations at Hanyang university hospital . Gastroenterol Jpn 1991 Jul; 26 (Suppl 3): 101-6.

10. Alatise OI, Arigbabu OA, Lawal OO, Adesunkanmi AK, Agbakwuru AE, Ndububa DA, Akinola DO. Endoscopic hemorrhoidal sclerotherapy using $50 \%$ dextrose water: a preliminary report. Indian J Gastroenterol 2009 Jan-Feb; 28(1): 31-32.

11. Kluiber RM, Wolf BG . Evaluation of anaemia caused by haemorrhoidal bleeding. Dis Colon Rectum 1994 Oct; 37(10): 1006-7 .

12. Johanson JF, Rimm A . Optimal nonsurgical treatment of haemorrhoids : a comperative analysis of infrared coagulation, rubber band legation and injection sclerotherapy . Am J Gastroenterol 1992 Nov; 87(11): 1600-6 